\title{
The seepage of a river into a valley filled with two layers of different permeabilities
}

\section{WARTENA}

Research division of the Nederlandsche Heidemaatschappij, Arnhem

\section{Summary}

Based on the assumptions of De Glee and Ernst, formulae have been developed for the seepage from a river in a valley with constant groundwater-level.

For a very wide valley the formulae can be simplified, in which case the formulae developed by Mazure have been obtained.

The results for a wide and a narrow valley filled with soil layers of the same thicknesses and permeabilities have been compared.

\section{Introduction}

The problem of a river giving seepage into a valley is a problem with which many people are concerned. One case was developed theoretically by Mazure (1926).

His assumptions were that the layer through which the water passes was thick, the potential of the deep groundwater at the beginning of the seepage area was known and the width of this area was infinite.

Making use of the assumptions of DE GLEE (1930) and ERNST (1956) - the latter introduced the radial resistance of the river - it was possible to solve the problem too, in the case of the layer through which the water passes being thin, the width of the valley is so small that the seepage at the end may not be lost sight of and the potential of the groundwater below the river dike in the second layer is unknown.

\section{Description and basic formulae}

In FIG. 1 one can see for what assumptions the calculations have been made. The rock bottom is horizontal. The first layer $B_{1}$ has a bad permeability $K_{1}$, the second layer $G_{2}$ has a good permeability $K_{2}$, for which $K_{2}>10 K_{1}$.

The thickness $D_{2}$ of $G_{2}$ is constant. The water in the layer $B_{1}$ has a constant level $h_{1}$ over the bottom of the valley, so the thickness of the water filled surface layer is of a constant thickness $D_{1}$.

In $G_{2}$ there is only a horizontal flow and in $B_{1}$ only a vertical flow in agreement with MAZURE, ERNST, i.a.

The river bottom is still in $B_{1}$, so the following basic formulae can be put down, when $Q$ is the total amount of seepage from the river to one side. Where the seepage $S=S(x)$, a function of the distance $x$ from the dike and $C=\frac{D_{1}}{K_{1}}$, the vertical Received for publication 2nd March, 1961. 
FIG. 1. The impermeable bedrock of the valley is overlain by a good permeable layer $G_{2}$. $A$ less permeable layer $\mathbf{B}_{1}$ is deposited over $\mathbf{G}_{2}$.

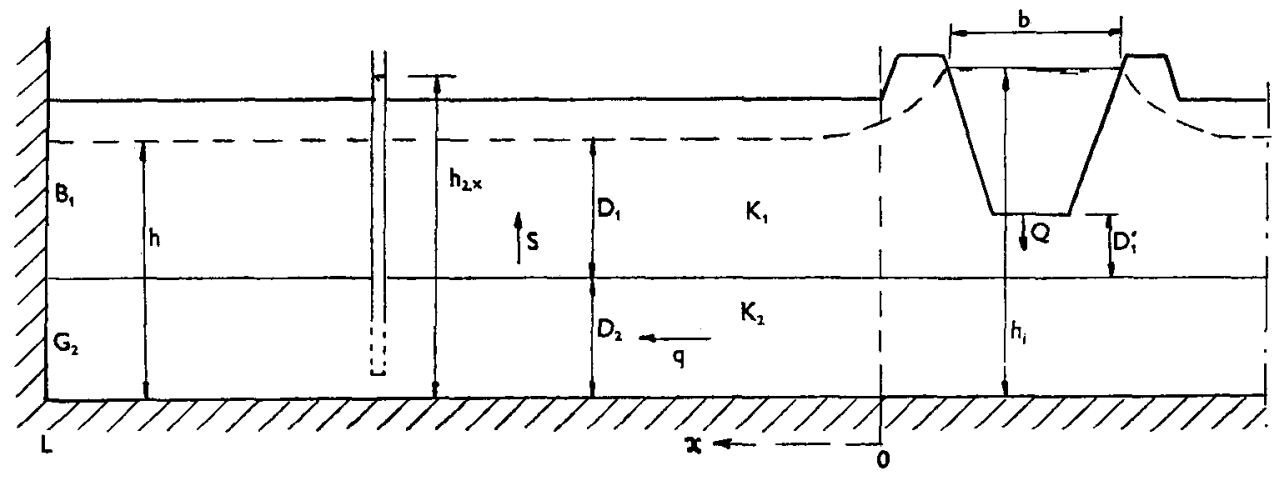

resistance of $B_{1}$ :

$$
\begin{aligned}
& s=-\frac{d q}{d x}=\frac{\mathrm{h}_{2, x}-h_{1}}{C} \\
& q=-K_{2} D_{2} \frac{d^{2} h_{2, x}}{d x^{2}}
\end{aligned}
$$

\section{Solution}

Simultaneous solution gives

$$
h_{2, x}-h_{1}=A e^{x / z_{0}}+B e^{-x / z_{0}}
$$

$z_{0}=\frac{1}{\sqrt{K_{2} D_{2} C^{\prime}}}=a$ characteristic length.

Together with the boundary conditions

as for $x=0$ we get $q=Q$ and

as for $x=L$ we get $q=0$

the integration constants $A$ and $B$ can be solved, so we get:

$$
q=\frac{Q}{e^{2 L \mid z_{0}}-1} e^{(2 L-x) / z_{0}}-e^{x / z_{0}}
$$

In equation (4) the total seepage $Q$ is still unknown.

We can put down

in which

$$
Q=\frac{h_{j}-h_{2,0}}{\gamma}
$$

$$
\gamma=W+\frac{D^{\prime}{ }_{1}}{K_{1} b^{\prime}}
$$

$W$ is the radial resistance and $\frac{D^{\prime} 1}{K_{1}}$ the vertical resistance between the bottom of the 
river and the highly permeable layer. $b^{\prime}$ is the width of the part of the river out of which water flows, contributing to the seepage $Q$.

With a decreasing $b^{\prime}$ one gets a decreasing $W$.

$\gamma$ has a minimum value.

The water will flow in such way, that $\gamma$ is minimal, which value can be calculated by trial and error.

ERNST will shortly be publishing something about the formulae for $W$ in various cases, elsewhere.

Together with the boundary conditions, solution of 3,4 and 5 gives

$$
\begin{aligned}
\mathrm{q} & =\frac{K_{2} D_{2}\left(h_{j}-h_{1}\right) \sinh \left\{(L-x) / z_{0}\right\}}{\gamma K_{2} D_{2} \sinh L / z_{0}+z \cosh L / z_{0}} \\
S & =\frac{K_{2} D_{2}\left(h_{j}-h_{1}\right) \cosh \left\{(L-x) / z_{0}\right\}}{\gamma K_{2} D_{2} \sinh L / z_{0}+\bar{z}_{0}^{2} \cosh L / z_{0}} \\
Q & =\frac{K_{2} D_{2}\left(h_{j}-h_{1}\right) \operatorname{tgh} L / z_{0}}{\gamma K_{2} D_{2} \operatorname{tgh} L / z_{0}+z_{0}}
\end{aligned}
$$

Working with big values of $L / z_{0}$ and $(L-x) / z_{0}$ with hyperbolical functions is difficult and may give use to great errors.

Approximation by means of the formulae $7 \mathrm{a}-9 \mathrm{a}$ is then preferable.

$$
\begin{aligned}
q & =Q e^{-x / z_{0}} \\
S & =Q e^{-x \mid z_{0}} / z_{0} \\
Q & =\frac{K_{2} D_{2}\left(h_{j}-h_{1}\right)}{\gamma K_{2} D_{2}+z_{0}}
\end{aligned}
$$$$
7 \mathrm{a}
$$

For $L \rightarrow$ in these formulae are exact.

The formulae 7a and $8 \mathrm{a}$ were developed by MAZURE (1936) in this form.

\section{Discussion}

In general the most important thing is to know the seepage at different distances of the river.

It is possible to do this graphically. In FIG. 2 two cases are calculated with the following data

$$
\begin{aligned}
& K_{1}=0,1 \mathrm{~m} \mathrm{day}-1 \\
& K_{2}=50 \mathrm{~m} \mathrm{day}-1 \\
& D_{1}=5 \mathrm{~m} \\
& D_{2}=4 \mathrm{~m}
\end{aligned}
$$

$$
\begin{aligned}
& D_{1^{\prime}}=2 \mathrm{~m} \\
& h=11,5 \mathrm{~m} \\
& h_{1}=9 \mathrm{~m} \\
& \gamma=1,291 \text { day } \mathrm{m}^{-1}
\end{aligned}
$$

This, together with $L=2,000 \mathrm{~m}$, for which $8 \mathrm{a}$ and with $L=200 \mathrm{~m}$, for which formula (8) was used, gave the two curves. Attention must be paid to the $K_{1}$ and $K_{2}$. Owing to the fact that in $B_{1}$ there is mainly a vertical flow and in $G_{2}$ mainly a horizontal flow, the vertical permeability in $B_{1}$ and the horizontal permeability in $G_{2}$ are of interest. 


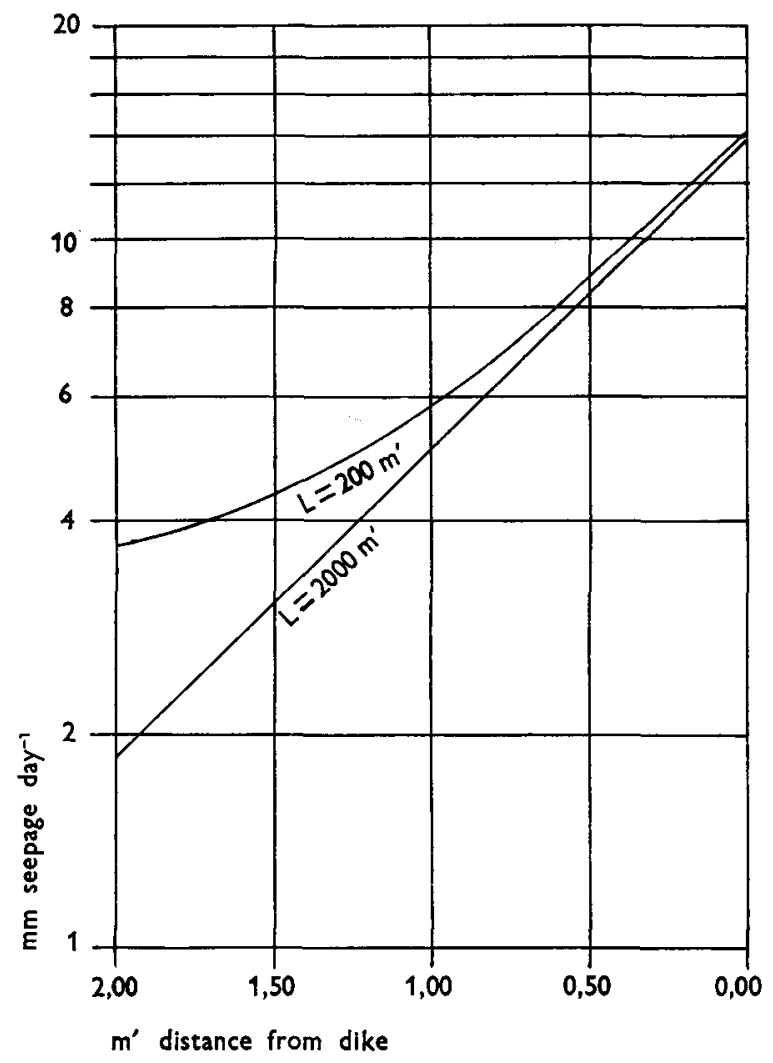

FIG. 2. The seepage from the river into the valley varies with the distance and depends on the width of the valley. For two widths of the valley the relationship is shown. $\mathrm{L}$ is the distance from the river to the rock shown in FIG. 1.

Especially when the permeabilities in $B_{1}$ are measured by the augerhole method or by a pump test, the event of greater horizontal than vertical permeability, too high values for $K_{1}$ are found.

\section{I T E R A T U R E}

ERNST, L. F.

1956 Calculation of the steady flow of groundwater in vertical GleE, G. J. DE

1930 Over grondwaterstromingen bij wateronttrekking door middel van putten. Thesis, Delft. In Dutch, 175 pp., 53 figs, 14 tables, references.

Mazure, J. P.

1936 Mededelingen betreffende Zuiderzeewerken. No. 5, p. 118. 